\title{
The Predictive Value of Biopsy of the Pancreas and Its Therapeutic Impact in Autoimmune Diabetes
}

\author{
Wael Nassar ${ }^{1,2^{*}}$, Mostafa A. Mostafa ${ }^{2}$ \\ ${ }^{1}$ Nephrology Department, Sahel Teaching Hospital, General Organization of Teaching Hospitals and Institutes \\ (GOTHI), Cairo, Egypt \\ ${ }^{2}$ Department of Internal Medicine and Diabetes, October Six University, Cairo, Egypt \\ Email: Hegaz wn@yahoo.com
}

Received 20 August 2014; revised 15 September 2014; accepted 6 October 2014

Copyright (C) 2014 by authors and Scientific Research Publishing Inc.

This work is licensed under the Creative Commons Attribution International License (CC BY). http://creativecommons.org/licenses/by/4.0/

(c) (i) Open Access

\begin{abstract}
Diabetes Mellitus is by definition an end-stage organ failure. Type 1 diabetes mellitus (T1DM) is an autoimmune disease. Auto-inflammatory infiltrate appears to characterize the insulitis associated with T2DM. Recently, in 2013, Eva Corpos and colleagues described a comprehensive composition of peri-islet capsules and their basement membrane (BM). Virtanen I, Otonkoski $T$ and Irving-Rodgers H.F. have reported similar descriptions few years earlier which have not been taken seriously as they deserve. Bluestone JA, Virtanen I and Irving-Rodgers H.F. and other colleagues reported that accumulation of the lymphocytes around the islets without invasion of the BM is the first step in disease induction (non-destructive insulitis phase). Invasion of the BM byleucocytic infiltration (destructive insulitis phase) occurs over a period of several years offering a good window for therapeutic intervention. Clinical symptoms appear only when $70 \%-90 \%$ of $\beta$-cell mass are destroyed. This data emphasize the importance of identification and classification of such pathologic features by performing a biopsy of the pancreas with histoimmunochemistry analysis at the pre-hyperglycemic stage in a high risk genetically predisposed autoimmune suspected patient which may at least in part help to achieve new therapeutic approaches and help in halting the progression to end stage pancreatic disease (ESPD) known as diabetes mellitus. In this review we are going to emphasize the predictive role biopsy of the pancreas can build up a solid gold standard tool in diagnosis, stage and therapeutically follow up autoimmune diabetes mellitus.
\end{abstract}

\section{Keywords}

Autoimmune Diabetes Mellitus, Biopsy of the Pancreas, Insulitis

\footnotetext{
${ }^{*}$ Corresponding author.
}

How to cite this paper: Nassar, W. and Mostafa, M.A. (2014) The Predictive Value of Biopsy of the Pancreas and Its Therapeutic Impact in Autoimmune Diabetes. Journal of Diabetes Mellitus, 4, 297-303. 


\section{Introduction}

Type 1 diabetes mellitus (T1DM) is an autoimmune disease which is a diverse group of chronic illnesses characterized by an immune responses directed against islets $\beta$-cell mass. Recently, auto-inflammatory infiltrate appears to characterize the insulitis associated with T2DM. Moreover, islet-reactive T cells responding to multiple islet proteins have been found in both T1DM patients and phenotypic T2DM patients with or without islet autoantibodies [1]-[3], emphasizing the need to implicate early immune-based therapeutic interventions in treatment of pre-hyperglycemic stage of diabetic patients and it should ideally be effective, long-lasting, with minimal side effects and better cure rates.

The ability to predict the development of autoimmune diabetes has been improved markedly with the combined use of genetic, metabolic testing, islet autoantibodies and assessment of $\beta$-cell mass [3]. Other parameters as circulating microvesicles and exosomes will be having a good predictive value in the near future.

However, T1DM has a strong genetic component, reflected by the observation that first-degree relatives have a higher risk than the general population. Three classes of class II HLA genes (DP, DQ, and DR) have the strongest association with T1DM. Certain genes as HLA-DR3 and HLA-DR4 (DQ3.1 in particular) are highly susceptible antigens most associated with diabetes and polymorphic variants of class II HLA genes determine $40 \%-60 \%$ of genetic susceptibility [4].

Metabolic dysregulation precedes overt autoimmunity in T1DM [5]. The Finnish DIPP cohort study [6], showed that changes in serum metabolites were found only in the children who later developed T1DM. These changes included reduced serum succinate, lyso-phosphatidyl-choline (lysoPC), phospholipids, and ketoleucine, as well as elevated glutamic acid. These reactive lipid by-products are capable of activating pro-inflammatory molecules [7] that function as a natural adjuvant for the immune system [8].

Four biochemically characterized islet autoantibodies have been recognized, namely insulin auto-antibodies (IAA), glutamic acid decarboxylase 65 (GAD-65) antibody or (GADA), tyrosine phosphatases insulinoma antigen (IA)-2 and IA-2b, also known as (ICA512) and the zinc transporter 8 (ZnT8) [9] [10]. The presence of a single islet autoantibody is associated with relatively low risk on long-term follow-up $(<5 \%)$, whereas two autoantibodies had a $68 \%$ risk and three auto-antibodies have an estimate of more than $90 \%$ of developing T1DM within 5 years [9]. For T1DM prediction, a combination of GAD65 and IA-2 for primary screening, followed by ICA and IAA testing, has been proposed [11]. However, autoantibodies can fluctuate or even completely disappear. However, the American Diabetes Autoimmunity Study in the Young (DAISY) showed that about 95\% of pre-diabetic children express anti-insulin autoantibodies, but only 50\% express insulin auto-antibodies at the time of diagnosis of T1DM [12]. This obviates the need for an adjuvant marker (biopsy for example) to facilitate the decision making to start immune-modulatory therapy.

Currently, the monoclonal IgM antibody IC2, which specifically binds to the surface of beta cells, might be the only reliable marker for noninvasive imaging and quantification of native beta cells [13]. Sufficient amount of $\beta$-cell mass at diagnosis, $\beta$-cell proliferating agents could be prescribed, whereas with significantly low $\beta$-cell mass other therapeutic options, as islets transplantation and stem cells trans-differentiation, are more likely.

\section{Histology of the Pancreas}

The pancreas is the main exocrine and endocrine gland of the digestive system. The exocrine part of the pancreas has closely packed serous acini. The secretions of the acini empty into ducts lined with a cuboidal epithelium, which transformed to stratified cuboidal in the larger ducts. The endocrine parts, islets of Langerhans, are clumps of secretory cells that contain its hormone-producing cells. Discovered in 1869 by German pathological anatomist Paul Langerhans at the age of 22 [14], the islets of Langerhans constitute approximately $1 \%$ to $2 \%$ of the mass of the pancreas. About one million islets distributed throughout the pancreas of a healthy adult human, each of which measures about $0.2 \mathrm{~mm}$ in diameter, each islet is composed of $2000-4000 \beta$-cells [15]. The islets are supplied by up to three arterioles, which form a branching network of fenestrated capillaries, into which the hormones are secreted. The islet is drained by about six venules, which pass between the exocrine acini to the interlobular veins [16].

Hormones produced in the islets of Langerhans are secreted directly into the blood flow by (at least) five types of cells. Alpha cells producing glucagon (15\% - 20\% of total islet cells), beta cells producing insulin and amylin (65\% - 80\%), delta cells producing somatostatin (3\% - 10\%), PP cells (gamma cells) producing pancreatic polypeptide (3\% - 5\%) and epsilon cells producing ghrelin $(<1 \%)$. Islets can influence each other through 
paracrine and autocrine communication, and beta cells are coupled electrically to other beta cells (but not to other cell types). Electrical activity of pancreatic islets cells in intact islets differs significantly from the behavior of dispersed cells [16].

\section{Immunohistochemistry of the Extracellular Matrix}

The extracellular matrix (ECM) of the pancreatic islets separates the secretory cells compartment and provides specific signals to control the cells function and survival [17]. The extracellular matrix of the islet is formed mainly of two types, basement membrane (BM), which function as a barrier limiting the trans-membrane crossmovement of cells and molecules and interstitial matrix (IM), which offers elasticity and flexibility to the islet cells. The basement membrane is formed mainly of collagens, laminins, nedogins and perlican. The nidogens are to stabilize the collagens and laminins, while the perlicans which are a Heparin-sulphate proteoglycans (HSPGs) by their large size (400 - $470 \mathrm{kDa})$ and side-chains known to act as a physical barrier to protect against the cell migration or cell invasion and can express adhesion ligands to prevent migrating leucocytes [18]. The IM layer is composed of fibrillar collagens, nonfibrillar collagens and noncollagenous glycol proteins, like fibronectin, tenascins, vitronectin, and chondroitin, ordermatan sulfate proteoglycans [19] [20].

There has been some confusion about the existence of a peri-islet basement membrane, due, in particular, to reports of discontinuous staining of basement membrane components around the islet periphery [21] [22], incomplete analyses resulting from a limited range of basement membrane-specific reagents, the close proximity of the acinar basement membrane and the presence of sub-endothelial basement membranes of the vasculature. The islet basement membrane exists and in the absence of enzymatic destructive insulitis, it is a continuous structure [16] [23].

\section{The Proposed Scenario of Autoimmune Diabetes: Figure 1}

The initial step in the development of autoimmune diabetes is leucocytic extravasation and aggregation from the peri-islet vessels in a slowly progressive inflammatory process. At this point clinical diabetes does not exist, penetration of the islet basement membrane by these leucocytes is crucial to proceed to destruction of the $\beta$-cell and as soon as the mass destruction approaches $70 \%-90 \%$ of the islets, clinical diabetes supervenes [24]. Although the leucocytic infiltration is wide spread in the pancreatic tissue, few islets shows basement membrane destruction and not others, indicating that these are two different processes [24]. The lack of destruction of basement membranes of nearby acini and of intra-islet capillaries, which have the same composition as the islet basement membrane, suggest that destruction is site-specific and localized to the immediate islet microenvironment [25]. Irving-Rodgers H.F. and colleagues proposed that perlican in particular, is essential for converting

(A) Non-destructive insulitis phase which is characterized by leukocyte extravasation from the peri-islet blood vessels

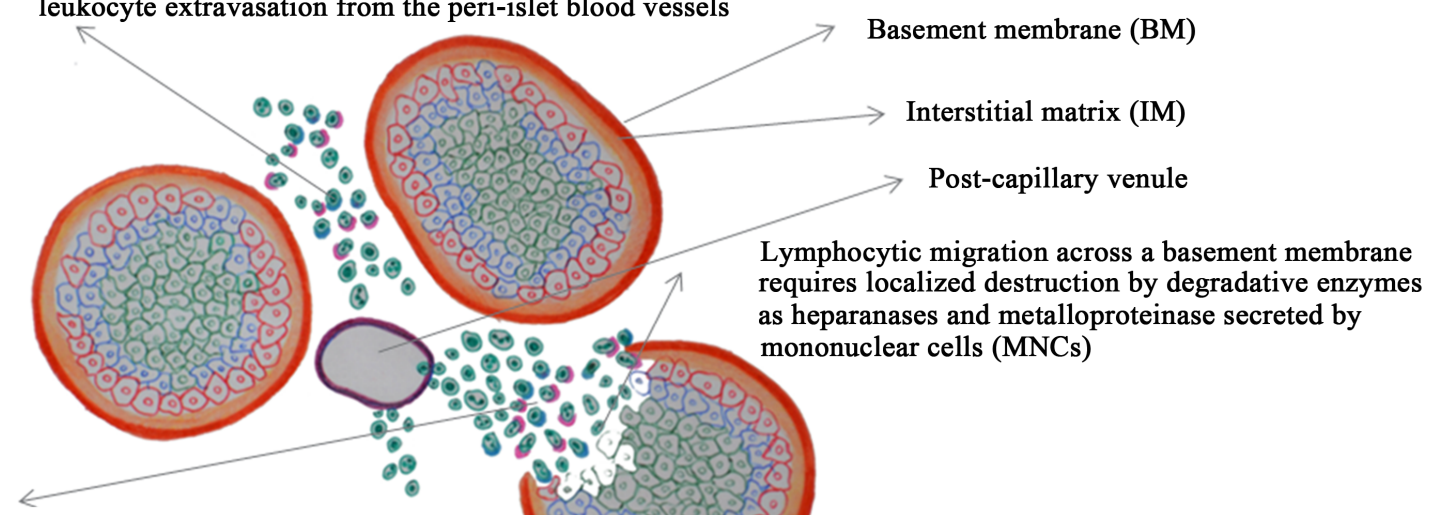

(B) Destructive insulitis phase, characterized by leucocyte penetration of the islet basement membrane.

Once inflammation had subsided, the peri-islet basement membrane (BM) and underlying interstitial matrix (IM) were shown to be reconstituted in the human, indicating that the cells producing the peri-islet BM are not lost due to inflammation

Figure 1. A flow diagram showing "the proposed scenario of autoimmune diabetes". 
non-destructive autoimmunity to destructive autoimmunity and the demise of islet beta cells and the development of clinical symptoms of type 1 diabetes [26]. Lymphocytic migration across a basement membrane requires localized destruction by degradative enzymes [26]. No changes were observed in the composition of the peri-islet basement membrane at or after the onset of type 1 diabetes, suggesting that it was not a change in composition that initiated or allowed leucocyte infiltration [27] [28], but the composition of the islet basement membrane will dictate the degradative enzymes needed to permit the migration of mononuclear cells (MNCs) across the islet basement membrane [29]. These enzymes may include heparanases which degrade heparansulphate (HS) and metalloproteinase which break down collagen [23] [26]. Eva Corpos and her group [24] attributed this invasion to cathepsins expression associated with macrophages at the front of leukocyte penetrating the peri-islet BM of type 1 diabetes [23] [25] and $\alpha$-cells, glucagon secretors, and other pancreatic cells are a potential source of peri-islet basement membrane (BM) components because of their tight association with the perislet BM in the reconstituted islets. Once inflammation had subsided, the peri-islet basement membrane (BM) and underlying interstitial matrix (IM) were shown to be reconstituted in the mouse and human, indicating that the cells producing the peri-islet BM are not lost due to inflammation [24], which opens a new port for therapeutic modality to halt progression of autoimmune diabetes.

\section{Biopsy of the Pancreas}

Ishida H. [30] and Akihisa I. [31] have demonstrated that laparoscopic pancreatic biopsy is a safe procedure in recent-onset type 1 diabetic patients. T-cell-predominant infiltration to islets (insulitis) and hyper-expression of major histocompatibility complex (MHC) class I antigens on islet cells were the two major findings observed in recent-onset type 1 diabetic patients. Anti-GAD and anti-IA-2 auto-antibodies are significantly of high predictive value for abnormal histology in the islets [32]. In another report, $\mathrm{CD}^{+} \mathrm{T}$-cells were predominant in insulitis lesions, and there was a close relationship between insulitis and overexpression of MHC class I antigens in islet cells [33]. The behavior of $\beta$-cell function could be predicted from the analysis of biopsy specimens [34] [35]. Report of the Expert Committee on the Diagnosis and Classification of Diabetes Mellituswas referring to patients with insulitis and/or hyperexpression of MHC class I antigens in islets as (type 1A) autoimmune diabetes or the patients without either of them as idiopathic (type 1B) [36] [37].

\section{Proposal and Conclusions}

In a genetically predisposed high risk patient, an inciting factor(s) which can be viral or bacterial infection either by itself or via an exosome from the distant infected cell [38] or through the B lymphocytes [39] reacting to the original infected cell. The $\beta$-islet cell introduces its antigenic epitope to the adaptive immune system which in turn starts to form different types of anti-insulin autoantibodies. It is yet unclear whether the initial release of $\beta$ cell auto-antigens is prompted by endogenous $\beta$-cell defects and/or an exogenous trigger, such as in hepatitis $\mathrm{C}$ viral infection [40].

Two important landmarks characterizing the natural history of clinical diabetes, non-destructive insulitis phase which is haracterized by leukocyte extravasation from the peri-islet blood vessels and destructive insulitis phase, characterized by leucocyte penetration of the islet basement membrane. From non-destructive to destructive phases, several years could have passed before the onset of hyperglycemia giving a good window for therapeutic intervention [41]. Moreover, the clinical diabetes will not present unless more than $90 \%$ of the islets have been destructed which, mostly, takes months to occur. It sounds logic that just detection of two or more of the islets autoimmune antibodies can be considered diagnostic for the autoimmune diabetes and the fraction of patients who have autoantibodies and have not progressed to develop autoimmune diabetes is probably attributed to the integrity of their immune system or lacking other contributing factors to augment the action of these autoantibodies. It is worthwhile to mention that not only $\beta$-cells are in direct contact with the islet basement membrane (BM), but there also other four types of cells that may play an important role in the mechanism of BM destruction [42]. Some researchers have been trying to study the impact of immunosuppression on progression of T1DM from different aspects; specific neutralizing vaccine against glutamic acid decarboxylase 65 (GAD-65) antibody (i.e., GAD-alum), non-specific B cell depleting agent as rituximab (monoclonal antibody against CD20) and non-specific $\mathrm{T}$ cell depleting agents as orthoclone (monoclonal antibodies against $\mathrm{CD} 3$ ) with limited but encouraging results possibly due to improper staging.

For lymphocytes to cross the basement membrane, a localized degenerative destructive enzyme is required 
[23]. The composition of the islet basement membrane will dictate the degenerative enzymes needed to be produced by insulitis mononuclear cells (MNCs) to permit their migration across the islet basement membrane. Leukocyte penetration of the peri-islet BM differs from leukocyte extravasation from blood vessels. This suggests that the ECM milieu influences the mode used by immune cells to infiltrate into tissues and raises novel possibilities for tissue-specific immune-modulatory therapies [43].

In conclusion, to date, non-of the current predictive parameters of autoimmune diabetes are strong enough to start immunosuppressive drug therapy in a yet normal individual. Proper staging on a solid base, biopsy of the pancreas with immunohistochemistry assay, in a genetically predisposed high risk patient with two or more autoantibodies will open up the gate for further histopathologic classification and hence allow better use of the already available therapeutic modalities and help in developing new once and clues lots of mysteries of autoimmune diabetes.

\section{Acknowledgements}

The authors gratefully acknowledge Rashad S. Barsoum, Professor of Internal Medicine and Nephrology, Faculty of Medicine, Cairo University, Egypt, for his unlimited help and support. We wish also to acknowledge Mayar W. N., who put our imagination onto real illustration.

\section{Conflict}

We, the authors of this review, declare that there is no conflict of interest that could be perceived as prejudicing the impartiality of the research. We fully declare that no financial or other potential conflict of interest.

\section{References}

[1] Donath, M.Y. and Shoelson, S.E. (2011) Type 2 Diabetes as an Inflammatory Disease. Nature Reviews Immunology, 11, 98-107. http://dx.doi.org/10.1038/nri2925

[2] Brooks-Worrell, B. and Palmer, J.P. (2011) Is Diabetes Mellitus a Continuous Spectrum? Clinical Chemistry, 57, 158-161. http://dx.doi.org/10.1373/clinchem.2010.148270

[3] Brooks-Worrell, B.M., Reichow, J.L., Goel, A., Ismail, H. and Palmer, J.P. (2011) Identification of Autoantibody-Negative Autoimmune Type 2 Diabetic Patients. Diabetes Care, 34, 168-173. http://dx.doi.org/10.2337/dc10-0579

[4] Eisenbarth, G.S. (2010) Banting Lecture 2009: An Unfinished Journey: Molecular Pathogenesis to Prevention of Type 1A Diabetes. Diabetes, 59, 759-774. http://dx.doi.org/10.2337/db09-1855

[5] Zhang, L. and Eisenbarth, G.S. (2011) Prediction and Prevention of Type 1 Diabetes Mellitus. Journal of Diabetes, 3, 48-53. http://dx.doi.org/10.1111/j.1753-0407.2010.00102.X

[6] Zhang, X.M., Wang, H.Y., Luo, Y.Y. and Ji, L.N. (2009) HLA-DQ, DR Allele Polymorphism of Type 1 Diabetes in the Chinese Population: A Meta-Analysis. Chinese Medical Journal, 122, 980-986.

[7] Ziegler, A.-G., Hummel, M., Schenker, M. and Bonifacio, E. (1999) Autoantibody Appearance and Risk for Development of Childhood Diabetes in Offspring of Parents with Type 1 Diabetes. The 2-Year Analysis of the German BabyDIAB Study. Diabetes, 48, 460-468. http://dx.doi.org/10.2337/diabetes.48.3.460

[8] Barker, J.M., Barriga, K., Yu, L., et al. (2004) Prediction of Autoantibody Positivity and Progression to Type 1 Diabetes: Diabetes Autoimmunity Study in the Young (DAISY). The Journal of Clinical Endocrinology Metabolism, 89, 3896-3902. http://dx.doi.org/10.1210/jc.2003-031887

[9] Bottazzo, G.F., Florin-Christensen, A. and Doniach, D. (1974) Isletcell Antibodies in Diabetes Mellitus with Autoimmune Polyendocrine Deficiencies. Lancet, 2, 1279-1283. http://dx.doi.org/10.1016/S0140-6736(74)90140-8

[10] Verge, C.F., Gianani, R., Kawasaki, E., et al. (1996) Prediction of Type I Diabetes in First-Degree Relatives Using a Combination of Insulin, GAD, and ICA512bdc/IA-2 Autoantibodies. Diabetes, 45, 926-933. http://dx.doi.org/10.2337/diab.45.7.926

[11] Orban, T., Sosenko, J.M., Cuthbertson, D., et al. (2009) Pancreatic Islet Autoantibodies as Predictors of Type 1 Diabetes in the Diabetes Prevention Trial-Type 1 (DPT-1). Diabetes Care, 32, 2269-2274. http://dx.doi.org/10.2337/dc09-0934

[12] Yu, L., Robles, D.T., Abiru, N., Kaur, P., Rewers, M., Kelemen, K. and Eisenbarth, G.S. (2000) Early Expression of Antiinsulin Autoantibodies of Humans and the NOD Mouse: Evidence for Early Determination of Subsequent Diabetes. Proceedings of the National Academy of Sciences of the United States of America, 97, 1701-1706.

http://dx.doi.org/10.1073/pnas.040556697 
[13] van Belle T.L., Coppieters, K.T. and von Herrath, M.G. (2011) Type 1 Diabetes: Etiology, Immunology and Therapeutic Strategies. Physiological Reviews, 91, 79-118. http://dx.doi.org/10.1152/physrev.00003.2010

[14] Langerhans, P. (1869) Beitragezurmikroscopischenanatomie der bauchspeichel druse. Inaugural-Dissertation, Gustav Lange, Berlin.

[15] Feldman, M., Friedman, L.S., Brandt, L.J. and Marvin, H. (2009) Sleisenger \& Fordtran’s Gastrointestinal and Liver Disease: Pathophysiology, Diagnosis, Management. 9th Edition, MD Consult, St. Louis.

[16] Pérez-Armendariz, M., Roy, C., Spray, D.C. and Bennett, M.V. (1991) Biophysical Properties of Gap Junctions between Freshly Dispersed Pairs of Mouse Pancreayic Beta Cells. Biophysical Journal, 59, 76-92. http://dx.doi.org/10.1016/S0006-3495(91)82200-7

[17] Yurchenco, P.D. and Patton, B.L. (2009) Developmental and Pathogenic Mechanisms of Basement Membrane Assembly. Current Pharmaceutical Design, 15, 1277-1294. http://dx.doi.org/10.2174/138161209787846766

[18] Pinkse, G.G.M., Bouwman, W.P., Jiawan-Lalai, R., Terpstra, O.T., Bruijn, J.A. and de Heer, E. (2006) Integrin Signaling via RGD Peptides and Anti- $\beta 1$ Antibodies Confers Resistance to Apoptosis in Islets of Langerhans. Diabetes, 55, 312-317. http://dx.doi.org/10.2337/diabetes.55.02.06.db04-0195

[19] Jones, P.L. and Jones, F.S. (2000) Tenascin-C in Development and Disease: Gene Regulation and Cell Function. Matrix Biology, 19, 581-596. http://dx.doi.org/10.1016/S0945-053X(00)00106-2

[20] Bluestone, J.A., Herold, K. and Eisenbarth, G. (2010) Genetics, Pathogenesis and Clinical Interventions in Type 1 Diabetes. Nature, 464, 1293-1300. http://dx.doi.org/10.1038/nature08933

[21] van Deijnen, J.H., Hulstaert, C.E., Wolters, G.H. and van Schilfgaarde, R. (1992) Significance of the Peri-Insular Extracellular Matrix for Islet Isolation from the Pancreas of Rat, Dog, Pig and Man. Cell and Tissue Research, 267, 139-146. http://dx.doi.org/10.1007/BF00318700

[22] Geutskens, S.B., Homo-Delarche, F., Pleau, J.M., Durant, S., Drexhage, H.A. and Savino, W. (2004) Extracellular Matrix Distribution and Islet Morphology in the Early Postnatal Pancreas: Anomalies in the Nonobese Diabetic Mouse. Cell and Tissue Research, 318, 579-588. http://dx.doi.org/10.1007/s00441-004-0989-0

[23] Virtanen, I., Banerjee, M., Palgi, J., et al. (2008) Blood Vessels of Human Islets of Langerhans Are Surrounded by a Double Basement Membrane. Diabetologia, 51, 1181-1191. http://dx.doi.org/10.1007/s00125-008-0997-9

[24] Korpos, E., Kadri, N., Kappelhoff, R., et al. (2013) The Peri-Islet Basement Membrane, a Barrier to Infiltrating Leukocytes in Type 1 Diabetes in Mouse and Human. Diabetes, 62, 531-542. http://dx.doi.org/10.2337/db12-0432

[25] Otonkoski, T., Banerjee, M., Korsgren, O., Thornell, L.E. and Virtanen, I. (2008) Unique Basement Membrane Structure of Human Pancreatic Islets: Implications for Beta-Cell Growth and Differentiation. Diabetes, Obesity and Metabolism, 10, 119-127. http://dx.doi.org/10.1111/j.1463-1326.2008.00955.x

[26] Irving-Rodgers, H.F., Ziolkowski, A.F., Parish, C.R., Sado, Y., Ninomiya, Y., Simeonovic, C.J. and Rodgers, R.J. (2008) Molecular Composition of the Peri-Islet Basement Membrane in NOD Mice: A Barrier against Destructive Insulitis. Diabetologia, 51, 1680-1688. http://dx.doi.org/10.1007/s00125-008-1085-X

[27] Valli, M.B., Serafino, A., Crema, A., et al. (2006) Transmission in Vitro of Hepatitis C Virus from Persistently Infected Human B-Cells to Hepatoma Cells by Cell-to-Cell Contact. Journal of Medical Virology, 78, 192-201. http://dx.doi.org/10.1002/jmv.20527

[28] Wang, R.N., Paraskevas, S. and Rosenberg, L. (1999) Characterization of Integrin Expression in Islets Isolated from Hamster, Canine, Porcine and Human Pancreas. Journal of Histochemistry Cytochemistry, 47, 499-506. http://dx.doi.org/10.1177/002215549904700408

[29] Parish, C.R. (2006) The Role of Heparan Sulphate in Inflammation. Nature Reviews Immunology, 6, 633-643. http://dx.doi.org/10.1038/nri1918

[30] Ishida, H. (1983) Peritoneoscopy and Pancreas Biopsy in the Diagnosis of Pancreatic Diseases. Gastrointestinal Endoscopy, 29, 211-218. http://dx.doi.org/10.1016/S0016-5107(83)72587-3

[31] Imagawa, A., Hanafusa, T., Tamura, S., Moriwaki, M., Itoh, N., Yamamoto, K., Iwahashi, H., Yamagata, K., Waguri, M., Nanmo, T., Uno, S., Nakajima, H., Namba, M., Kawata, S., Miyagawa, J. and Matsuzawa, Y. (2001) Pancreatic Biopsy as a Procedure for Detecting in Situ Autoimmune Phenomena in Type 1 Diabetes. Close Correlation between Serological Markers and Histological Evidence of Cellular Autoimmunity. Diabetes, 50, 1269-1273. http://dx.doi.org/10.2337/diabetes.50.6.1269

[32] Itoh, N., Hanafusa, T., Miyazaki, A., Miyagawa, J., Yamagata, K., Yamamoto, K., Waguri, M., Imagawa, A., Tamura, S., Inada, M., Tarui, S., Kono, N. and Matsuzawa, Y. (1993) Mononuclear Cell Infiltration and Its Relation to the Expression of Major Histocompatibility Complex Antigens and Adhesion Molecules in Pancreas Biopsy Specimens from Newly Diagnosed Insulin-Dependent Diabetes Mellitus Patients. Journal of Clinical Investigation, 92, 2313-2322. http://dx.doi.org/10.1172/JCI116835

[33] Imagawa, A., Hanafusa, T., Miyagawa, J., Matsuzawa, Y., for the Osaka IDDM Study Group (2000) A Novel Subtype 
of Type 1 Diabetes Mellitus Characterized by a Rapid Onset and an Absence of Diabetes-Related Antibodies. The New England Journal of Medicine, 342, 301-307. http://dx.doi.org/10.1056/NEJM200002033420501

[34] Imagawa, A., Hanafusa, T., Itoh, N., Waguri, M., Yamamoto, K., Miyagawa, J., Moriwaki, M., Yamagata, K., Iwahashi, H., Sada, M., Tsuji, T., Tamura, S., Kawata, S., Kuwajima, M., Nakajima, H., Namba, M. and Matsuzawa, Y. (1999) Immunological Abnormalities in Islets at Diagnosis Paralleled Further Deterioration of Glycaemic Control in Patients with Recent-Onset Type I (Insulin-Dependent) Diabetes Mellitus. Diabetologia, 42, 574-578. http://dx.doi.org/10.1007/s001250051197

[35] The Expert Committee on the Diagnosis and Classification of Diabetes Mellitus (1997) Report of the Expert Committee on the Diagnosis and Classification of Diabetes Mellitus, Diabetes Care, 20, 1183-1197.

[36] Imagawa, A., Hanafusa, T., Miyagawa, J. and Matsuzawa, Y. (2000) A Proposal of Three Distinct Subtypes of Type 1 Diabetes Mellitus Based on Clinical and Pathological Evidence. Annals of Medicine, 32, 539-543. http://dx.doi.org/10.3109/07853890008998833

[37] Papaccio, G., Latronico, M.V., Pisanti, F.A., Federlin, K. and Linn, T. (1998) Adhesion Molecules and Microvascular Changes in the Nonobese Diabetic (NOD) Mouse Pancreas. An NO-Inhibitor (L-NAME) Is Unable to Block Adhesion Inflammation-Induced Activation. Autoimmunity, 27, 65-77. http://dx.doi.org/10.3109/08916939809008037

[38] Papaccio, G., Pisanti, F.A., Montefiano, R.D., Graziano, A. and Latronico, M.V. (2002) Th1 and Th2 Cytokines Exert Regulatory Effects upon Islet Microvascular Areas in the NOD Mouse. Journal of Cellular Biochemistry, 86, 651-664. http://dx.doi.org/10.1002/jcb.10250

[39] Yadav, R., Larbi, K.Y., Young, R.E. and Nourshargh, S. (2003) Migration of Leukocytes through the Vessel Wall and Beyond. Thrombosis and Haemostasis, 90, 598-606.

[40] Barsoum, R.S. (2007) Hepatitis C Virus: From Entry to Renal Injury-Facts and Potentials. Nephrology Dialysis Transplantation, 22, 1840-1848. http://dx.doi.org/10.1093/ndt/gfm205

[41] Masciopinto, F., Giovani, C., Campagnoli, S., et al. (2004) Association of Hepatitis C Virus Envelope Proteins with Exosomes. European Journal of Immunology, 34, 2834-2842. http://dx.doi.org/10.1002/eji.200424887

[42] Ondr, J.K. and Pham, C.T. (2004) Characterization of Murine Cathepsin W and Its Role in Cell-Mediated Cytotoxicity. The Journal of Biological Chemistry, 279, 27525-27533. http://dx.doi.org/10.1074/jbc.M400304200

[43] Hsing, L.C., Kirk, E.A., McMillen, T.S., et al. (2010) Roles for Cathepsins S, L, and B in Insulitis and Diabetes in the NOD Mouse. Journal of Autoimmunity, 34, 96-104. http://dx.doi.org/10.1016/j.jaut.2009.07.003

\section{List of Abbreviations}

\begin{tabular}{|c|c|c|c|}
\hline T1DM & Type 1 Diabetes Mellitus & ICA & Islet Cell Autoantibody \\
\hline T2DM & Type 2 Diabetes Mellitus & $\mathrm{DPT}$ & Diabetes Prevention Trial \\
\hline ESPD & End-Stage Pancreatic Disease & $\mathrm{BM}$ & Basement Membrane \\
\hline LADA & Latent Autoimmune Diabetes of Adult & IM & Interstitial Matrix \\
\hline HLA & Human Leucocytic Antigen & DAISY & Diabetes Autoimmunity Study in the Young \\
\hline DKA & Diabetic Ketiacidosis & HSPG & Heparin-Sulphate Proteoglycans \\
\hline LysoPC & Lyso-Phosphatidyl-Choline & $\mathrm{KDa}$ & Kilo Dalton \\
\hline GAD-65 & Glutamic Acid Decarboxylase-65 & HS & Heparan Sulphate \\
\hline IA & Insulinoma Antigen & MP & Metalloproteinase \\
\hline IAA & Insulin Auto-Antibodies & MNCs & Mono Nuclear Cells \\
\hline ZnT8 & Zinc Transporter 8 & & \\
\hline
\end{tabular}


Scientific Research Publishing (SCIRP) is one of the largest Open Access journal publishers. It is currently publishing more than 200 open access, online, peer-reviewed journals covering a wide range of academic disciplines. SCIRP serves the worldwide academic communities and contributes to the progress and application of science with its publication.

Other selected journals from SCIRP are listed as below. Submit your manuscript to us via either submit@scirp.org or Online Submission Portal.
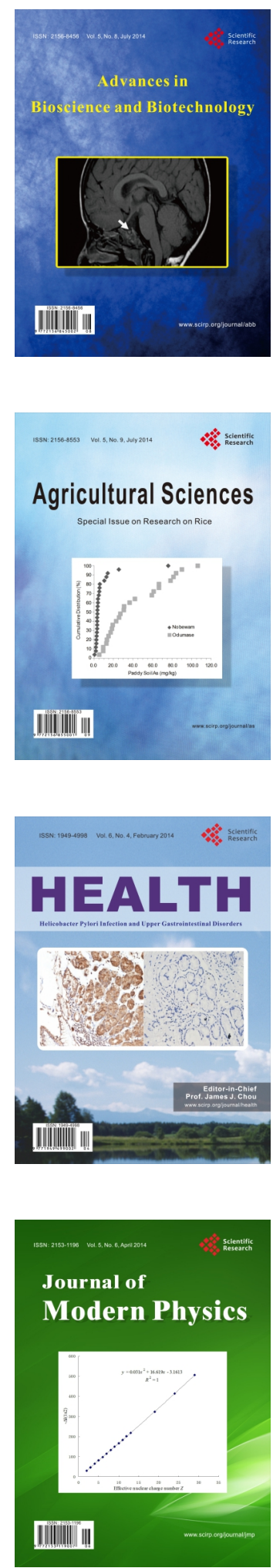
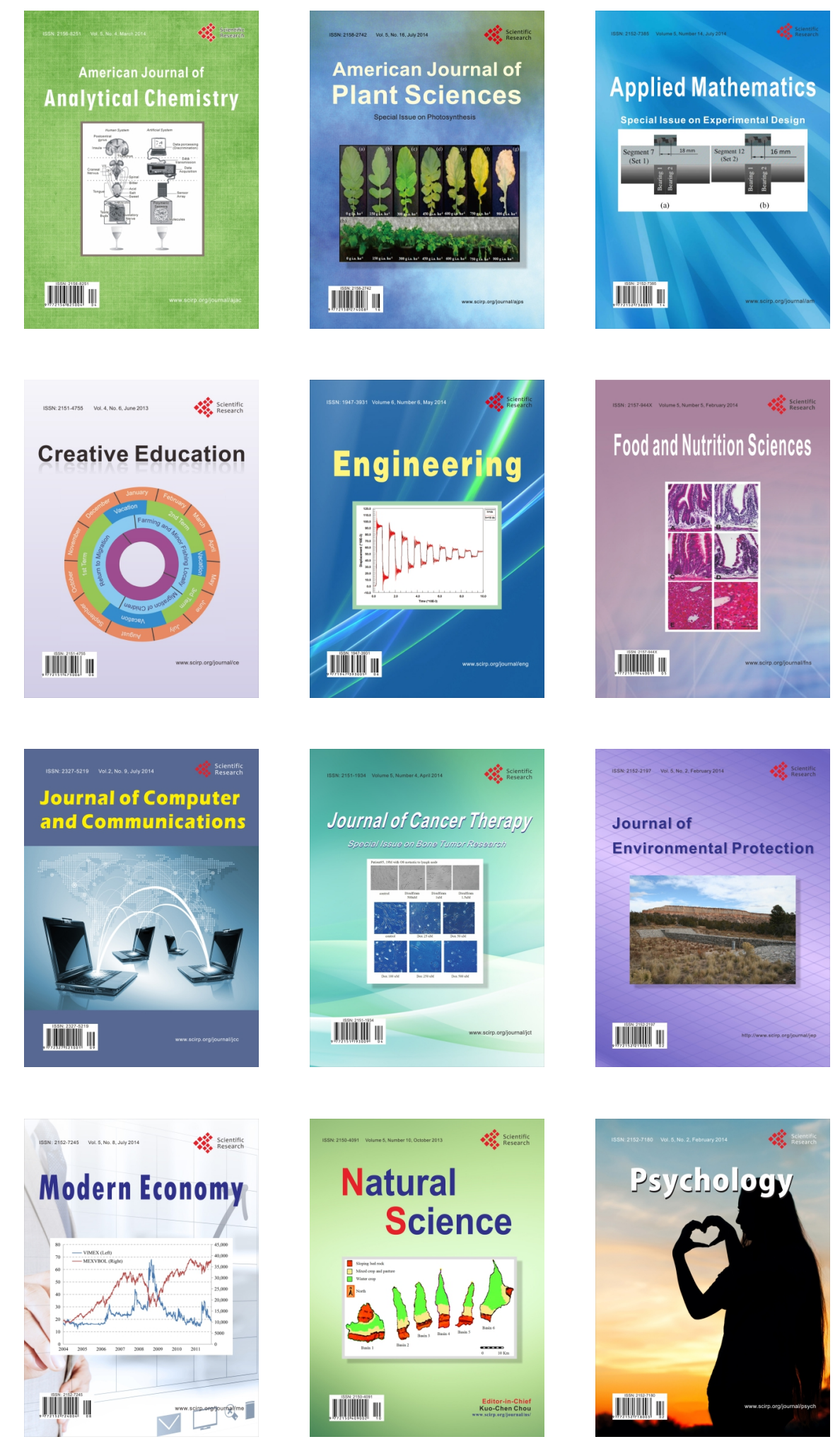